\title{
ADORNO LEITOR DE FREUD: Para além da coerção mítica da razão?
}

\author{
Luiz Calmon Nabuco Lastória \\ lacalmon@uol.com.br
}

Não seria demasiado afirmar que, concomitante ao avanço das neurociências, também a psicanálise se tornou ainda mais premente enquanto um discurso orientado no sentido de acolher o que há de mais singular na experiência humana. Refiro-me precisamente à capacidade de desejar como condição sine qua non do ser que se diz "homem", àquilo que, por sua própria natureza, não se deixa capturar pelo desenvolvimento inexorável da racionalidade científica. Devemos hoje comparar a potência da teoria psicanalítica à de um vértice prismático capaz de proceder à decomposição espectral da gama de sintomas que afetam o sujeito contemporâneo. Pois, na contramão de toda farmacopeia demandada pela sociedade capitalista tornada "psicoativa", acentuadamente nas duas últimas décadas, vem se multiplicando os esforços de leituras no âmbito dessa teoria quanto ao que parece ser o mais recente tributo imposto pela cultura hodierna, visando assegurar a manutenção dos fragilizados vínculos sociais.

1. O papel dos fármacos no tratamento em larga escala das depressões em populações juvenis, tal como atesta o artigo "Depressão e imagens do Novo Mundo" de M. R. Kehl (NOVAES, 2007), assim como o chamado bullying em meio aos escolares, hoje bastante difundido pelos mass media ilustram claramente essa tendência. 
Nesse vasto rol de leituras interpretativas possíveis, cuja função primordial tem sido a de alimentar os debates referentes tanto à teoria quanto à clínica psicanalítica, situa-se outra vertente de pensamento bastante sui generis. Muito embora não emane do setting clínico, nem muito menos almeje informá-lo, essa vertente encontrou nas formulações teóricas de Freud um dos seus sustentáculos basilares. Trata-se da Teoria Crítica da Sociedade tal como fora compreendida pela primeira geração do Institut für Socialforschung, fundado em 1923 na cidade de Frankfurt.

É sabido que em 1931, por ocasião da posse no cargo de diretor desse Instituto, Max Horkheimer enfatizou em seu discurso a necessidade da "teoria social", isto é, da filosofia e da sociologia tomadas em conjunto, atacar as relações entre economia, desenvolvimento psíquico e as alterações verificadas no ambiente cultural da época. Para tanto, Horkheimer aludiu à necessidade de integração dos avanços alcançados pelas ciências burguesas, sobretudo pela psicologia (tendo em vista a psicanálise), o que deveria ocorrer levando-se em consideração a "cláusula materialista" que norteava a construção de uma teoria geral da sociedade. Através desse programa maior, Horkheimer pretendia estabelecer as linhas de força, no plano epistemológico, que resultassem numa equação dialética entre as dimensões da teoria e da empiria em meio ao cenário político europeu pré-fascista.

Desde então, muitas das ideias capitais da psicanálise ${ }^{2}$ serviram para municiar um acurado diagnóstico quanto ao antiquíssimo problema da dominação no horizonte de um processo histórico-cultural de longo alcance. De outra parte, o intuito de atacar com o auxílio da psicanálise a relação entre economia, desenvolvimento psíquico e as alterações verificadas no ambiente cultural orientou a elaboração da teoria crítica tanto no contexto europeu quanto no período do exílio estadunidense. Longe de pretender esgotar o modo pelo qual a conceituação psicanalítica permeou o intrincado processo de elaboração dessa teoria nos moldes de

2. R. Wiggershaus sublinhou que: "A psicanálise freudiana, à qual, com exceção de Fromm, Horkheimer e Adorno deviam também um bom número de suas ideias mais fecundas, constituía antes a continuação dos autores pessimistas da época burguesa, orientados para a psicologia e a antropologia" (WIGGERSHAUS, 2002, pp. 214-215). Com o propósito de enfatizar a extensão dessa dívida de Horkheimer e de Adorno em relação à psicanálise mencionada por Wiggershaus sirvo-me de uma bela imagem retirada de um dos capítulos do livro Lembrar, Escrever, Esquecer, de J. M. Gagnebin, empregada topicamente pela autora para elucidar a presença de Freud no ensaio de Adorno "O que significa elaborar o passado?". Trata-se de um "palimpsesto"; isto é: a imagem de um pergaminho cuja mensagem fora raspada para dar lugar à outra inscrição que lhe sobreveio. 
um projeto intelectual partilhado entre Horkheimer e Adorno, restrinjome ao exame de algumas particularidades inerentes a essa presença, sobretudo a partir da leitura realizada por Adorno do texto freudiano.

Em que pese à obra Dialética do Esclarecimento expressar de forma mais bem acabada o núcleo teórico do projeto a que nos referimos há pouco, para uma melhor aproximação do tema aqui tratado não se deve perder de vista as diferentes motivações de ordem intelectual pelas quais se movia cada um dos parceiros no interior do grupo que dava corpo ao Instituto. Enquanto Horkheimer dirigia seus interesses para a edificação de uma "teoria crítica da sociedade", sob a forma de um work in progress compreendendo a dialética como um tipo particular de "pensamento operado por totalidades relativas” (WIGGERSHAUS, 2002, p. 217), Adorno, por sua vez, voltava seu interesse para o plano da estética e para a situação social da arte $^{3}$. Conforme notou R. Wiggershaus, para Adorno, na esteira do pensamento de K. Marx grafado na Crítica da Filosofia do Direito de Hegel, a dialética significava "forçar aquelas relações petrificadas a dançar, cantando-lhes a sua própria melodia" (apud WIGGERSHAUS, 2002, p. 217). Ou ainda, na trilha aberta por seu amigo Walter Benjamin: "a possibilidade de desmitologizar e desencantar um vasto leque de fenômenos contemporâneos” (WIGGERSHAUS, 2002, p. 217).

Como se sabe, W. Benjamin no Passagenwerk soubera ver, na ousadia das criações arquitetônicas propiciadas pelo desenvolvimento industrial do século XIX, o caráter fetichizante da cultura burguesa sob a forma de "fantasmagorias", aspecto esse que conferia à modernidade uma tonalidade ainda mítica. Aliás, desde o seu trabalho sobre as Origens do Drama Barroco Alemão - Ursprung des deutschen Trauerspiels ele já havia sensibilizado Adorno para a fecundidade da idéia de uma história natural (Naturgeschichte), compreendida como uma súbita mudança de perspectiva: ver o novo no antigo e vice-versa, de modo que o "verdadeiramente novo" se restringiria à ultrapassagem do "mundo da natureza quando o espírito se reconhece como natureza" (WIGGERSHAUS, 2002, p. 126). Ideia que, como veremos, apontará para uma peculiar apropriação dialética da teoria das pulsões de Freud

3. Tal diferenciação nos permite distinguir diferentes modos de apropriação da teoria psicanalítica, tais como: na investigação preliminar sobre o anti-semitismo que se integrou à Dialética do Esclarecimento, e cujo desdobramento empírico foi realizado nos EUA ensejando a publicação da importante obra de psicologia social A Personalidade Autoritária na década de cinquenta, por um lado, e no emprego da psicanálise pelo esteta Adorno no sentido de conferir voz à particularidade do objeto artístico, por outro. 
enquanto um dos ingredientes necessários à elaboração da Teoria Crítica.

No entanto, acompanhando o trajeto biográfico de Adorno ${ }^{4}$ percebese que, não obstante o seu prematuro fascínio pelas inversões próprias ao pensamento dialético, que vieram justamente a se tornar o traço decisivo e o mais refinado do conjunto de sua obra, o que o cativara em princípio no contato com os escritos de Freud foi um motivo típico do iluminismo: possibilitar o acesso do material inconsciente à consciência. Motivo esse que adquiriu contornos mais bem delineados no trabalho concluído no verão de 1927 para obtenção de sua Habilitationsschrift, sob orientação de Hans Cornelius, intitulado "O Conceito de Inconsciente na Teoria Transcendental do Entendimento" (Unbewussten in der transcendentalen Seelenlehre)5.

Nesse trabalho, conforme expõe S. Buck-Morss, Adorno procurou argumentar que na Crítica da Razão Pura de Kant, mais especificamente na seção sobre os "paralogismos", estava descartada uma psicologia ontológica do inconsciente, sem que ao menos se discutisse a pertinência de uma psicologia formulada do ponto de vista da razão. Otrabalhoiniciava com "una crítica imanente de Schopenhauer, y de los Lebensphilosophen posteriores, que daban cuenta del inconsciente construyendo una metafísica de lo irracional" (BUCK-MORSS, 1981, p. 55). E prosseguia tentando demonstrar que os requisitos para o estabelecimento de uma teoria empírica do inconsciente, compatível com o neo-kantismo de seu professor, se encontravam exatamente na psicanálise de Freud ${ }^{6}$.

4. Numa carta escrita por Adorno a Benjamin, datada de 5 de dezembro de 1934, Adorno registra o que parece ter sido um de seus primeiros contatos mais sistemáticos com a teoria psicanalítica: "Conheço San Remo desde 1927, a primeira vez para uma breve estadia com Gretel, e posteriormente sozinho; foi o período em que estive ocupado com Freud"(LONITZ, H., 1999, p. 63).

5. Argumento reforçado pelo seguinte comentário de R. Wiggerhaus: "Eleinterpretava o conceito de inconsciente ora como um marco da consciência, ora como a denominação dos estados inconscientes que se poderiam trazer ao consciente" (WIGGERSHAUS, 2002, p. 113$)$.

6. Em que pese o seu trabalho não ter sido aceito por H. Cornelius, Adorno parece não ter arrefecido quanto à ideia de se servir da teoria psicanalítica para conferir certa materialidade à filosofia de Kant. Ao referir-se à lei moral kantiana na Dialética Negativa, de modo a revelar a face coercitiva embutida na própria noção de liberdade tal como proposta pelo idealismo, lemos: "Os traços coercitivos inseridos por Kant em sua doutrina da liberdade foram recolhidos na coerção real oriunda da consciência moral. A irresistibilidade empírica da consciência psicologicamente existente, do supereu, lhe garante, contra o seu princípio transcendental, a facticidade da lei moral que, mesmo segundo Kant, enquanto fundação da moral autônoma, precisaria ser igualmente desqualificada por ela como pulsão heterônoma" (ADORNO, 2009, p. 226). 
Nesse mesmo trabalho, referindo-se explicitamente ao texto freudiano, Adorno argumentara que: "La terapia se esfuerza por ser nada más que conocimiento"; "su meta era el 'desencantamiento' del inconsciente a través de la exposición de la lógica interna de sus manifestaciones - actos fallidos [...], sueños, síntomas neuróticos - y tornarlas accesibles al nivel consciente, a la comprensión racional" (apud BUCK-MORSS, 1981, p. 56). Uma leitura sem dúvida autorizada pela pena do próprio Freud em diversas passagens de sua obra e conforme aos dispositivos centrais estruturantes de sua clínica, a saber: rememoração, verbalização e simbolização reflexiva.

Não obstante as implicações relativas a essa compreensão do inconsciente retornarem à cena de modo bastante atenuado na Dialética do Esclarecimento, isso devido ao desenvolvimento de uma crítica mordaz ao pensamento identitário, cuja contraface psicológica já apontava para certa relativização do eu como instância cognoscitiva ${ }^{7}$, sobretudo nos últimos trabalhos de Adorno, não se pode negligenciar o fato de que elas tocam o objeto mesmo sobre o qual se funda a teoria psicanalítica. E é nesse sentido que a perspectiva inaugurada pela Teoria Crítica nos parece perpetuar, ainda que não sem ambiguidades, dois problemas deixados em aberto por Freud. O primeiro diz respeito ao estatuto do inconsciente e o segundo, à possibilidade de ampliação dos horizontes da consciência mediante procedimentos orientados para a simbolização reflexiva.

Sabemos do enorme empenho de Freud em tentar provar - no stricto sensu da verificação de uma hipótese - a existência do inconsciente junto ao ambiente científico de sua época. Sob a provável influência de seu admirado professor de filosofia Franz Brentano e comungando com a recepção de Kant por renomados cientistas como Fechner, Helmholtz e Hertz, Freud lançou mão do modelo energético, então predominante na física e na química, combinando-o com certa exigência de visualização topológica inspirada na geometria, para ordenar o "campo fenomenal" constituído pelo material clínico de que dispunha. Disso resultou o esboço não apenas da primeira tópica composta do inconsciente, pré-consciente e consciente, mas de toda sua metapsicologia. Isto é: "descrever um processo psíquico em suas relações dinâmicas, topológicas e econômicas" (FREUD, 2010, p. 121).

7. Numa passagem da Dialética do Esclarecimento Horkheimer e Adorno argumentam que: "O ego idêntico é o produto mais tardio da projeção. [...] [E]le se desenvolveu como uma função unitária e, ao mesmo tempo, excêntrica. Todavia, mesmo como ego objetivado de maneira autônoma, ele só é o que o mundo-objeto é para ele" (HORKHEIMER e ADORNO, 1994, p. 176). 
Daí também uma das ideias mestras para a edificação do seu constructo maior segundo a qual, na região inconsciente do aparelho psíquico, as "representações das coisas" coabitam desvinculadas das “representações das palavras”. E, por atraírem-se umas na direção das outras elas conformariam um tipo muito particular de pensamento capaz de operar por deslocamentos e condensações. Os "processos primários", assim os denominara Freud, ocorrem sob a regência do princípio de prazer em contraposição ao princípio de realidade. Observemos de passagem que, nesse ponto, seu pensamento permaneceu caudatário do conceito de "representação" (Vorstellung), conceito esse que possui uma longa história na tradição das filosofias da consciência, para se referir justamente ao inconsciente como agente psíquico pensante, ainda que se admitisse que essa modalidade de pensamento não se vincula a nenhuma referência objetiva no plano da realidade e nem se articula a partir de categorias lógicas.

Sabemos ainda que o argumento de Freud em favor da existência do inconsciente está baseado em evidências clínicas, o que, por sua vez, pressupõe as relações de transferência entre dois sujeitos. No seu artigo intitulado "O Inconsciente", de 1915, pode-se ler: "Um ganho em sentido e coerência é motivo plenamente justificado para irmos além da experiência imediata. Se além disso pudermos edificar sobre a hipótese do inconsciente uma prática bem sucedida, mediante a qual influímos no curso dos processos conscientes, teremos nesse sucesso uma prova indiscutível da existência daquilo suposto" (FREUD, 2010, p. 102). No entanto, sabemos também o quanto essa prova permaneceu problemática não apenas pelos insucessos clínicos experimentados pelo próprio pai da psicanálise, mas sobretudo porque, como observou Z. Loparic a propósito da tentativa de Freud de fornecer explicações dinâmicas sobre os sintomas: "Isso não é uma prova da verdade objetiva da tese do inconsciente dinâmico, e sim de sua utilidade heurística e explicativa dentro do quadro metodológico preferido por Freud" (KNOLBLOCH, 1991, pp. 51-52).

Ainda que se possa objetar em favor da especificidade da noção freudiana de "dinâmica”, como o fez R. $\mathrm{Mezan}^{8}$, enquanto jogo pulsional

8. Quanto a esse ponto, R. Mezan foi enfático ao argumentar que "o 'ponto de vista dinâmico’ não é em absoluto uma postura simplesmente metodológica; ao contrário, é a formalização em termos conceptuais de uma postura ontológica, a categorização abstrata de uma série de fenômenos que se dão na realidade e que exigem, como seu princípio e sua condição de possibilidade, a afirmação da existência igualmente real do inconsciente dinâmico" (KNOLBLOCH, 1991: 67). 
e de natureza essencialmente conflituosa, fator esse determinante da psique humana enquanto tal, permanece o imbróglio causado pela hipótese do inconsciente quando perscrutada a partir dos pressupostos científico-iluministas, contraditoriamente adotados por Freud.

Quanto à possibilidade do tratamento analítico levar a uma ampliação dos horizontes da consciência suspendendo o recalque, diremos apenas que nos termos do próprio Freud o material inconsciente não constitui um fenômeno transitório entre o estado de latência e sua manifestação. Pelo contrário, constitui justamente aquilo que não pode vir a ser consciente. Enquanto um outro modo de funcionamento da vida psíquica, e isso vale tanto no caso do analisando como no do analista, o inconsciente se manifesta ao longo do tratamento analítico, mas nem por isso se torna consciente. Pois enquanto o fluxo da consciência pressupõe um movimento contínuo de antecipação de sentidos fornecidos por algum saber representável para o sujeito, o inconsciente pressupõe o inverso, ou seja: aqueles processos psíquicos cujo sentido não pode ser, de modo algum, antecipado. Isso quer dizer que tais processos são verdadeiramente "sintomáticos" muito além dos quadros nosológicos estabelecidos pela medicina. E o são na medida mesma em que interrogam os sentidos já constituídos pelos saberes acessíveis à consciência. Posto isso, podemos concordar com A. Juranville, ao concluir que a genialidade de Freud foi exatamente a de criar novos sentidos para os sintomas em voga na sua época, com a proposição de seu constructo hipotético maior - o inconsciente -, ao invés de simplesmente conformá-los ao existente em termos de normas e saberes.

Ao invés de insistirmos em desdobrar ainda mais as consequências decorrentes desse motivo iluminista convergente entre certo Freud e certo Adorno, talvez seja mais oportuno nos indagarmos sobre o estatuto de verdade da psicanálise, bem como de sua possível convergência oblíqua com a teoria crítica, recorrendo a uma das diversas passagens em que as palavras de Freud nos soam quase como "provocações". Refirome à conferência XXXII publicada sob o título "Novas conferências introdutórias à psicanálise" em 1933, onde ele se refere textualmente à sua teoria das pulsões como sendo a "nossa mitologia". Ora, do lado de Freud poderíamos interpelar pelo significado dessa colocação mais do que suspeita ao olhar iluminista. E, do lado de Adorno, restaria saber como a teoria das pulsões assumida nos referidos termos pelo pai da psicanálise poderia se integrar ao seu intento de "desmitologizar um vasto leque de fenômenos contemporâneos".

Gostaria de sugerir, como uma via possível para adentrarmos o cerne do problema que possibilita tais indagações, que persigamos algumas 
das afinidades eletivas existentes entre os discursos psicanalítico, de um lado, e mitopoético, de outro. Por essa via talvez possamos visualizar uma zona de intersecção positiva delineada entre a racionalidade própria ao mito e o esclarecimento moderno. Isto é: identificar algo na primeira que possa ser subtraída de sua presença meramente coercitiva e obstrutora no transcurso da Aufklärung em direção à emancipação. Suspeita já identificada por J. M. Gagnebin e justificada com as seguintes palavras: "Ela [a autora se refere aqui à "irresolução" perceptível na Dialética do Esclarecimento quanto ao estatuto do mito] aponta para a dificuldade do pensamento esclarecido, em particular do pensamento esclarecido de esquerda, de se confrontar com a força dessa dimensão chamada de mítica e, no mais das vezes, associada ao irracionalismo e ao absurdo. Associação que aliás só aprofunda o problema, porque se trata então de compreender porque o irracional é tão poderoso, de fato, nas decisões dos homens, esses animais racionais" (GAGNEBIN, 2006, p. 64).

Temos notícia da fascinação de Freud pela mitologia florescida no período arcaico da Hélade. Fato esse que, se tivermos em conta o seu desejo confesso de se tornar um eminente cientista, seremos tentados a filtrar tal reclamo por meio de uma das teses centrais, e bastante conhecida, exposta por Horkheimer e Adorno na Dialética do Esclarecimento, que consiste em afirmar que se o mito já era a forma primeva assumida pelo esclarecimento, isto é, pelo cânone racional dado ao pensamento científico que nos acompanha desde os alvores da modernidade, esse, por sua vez, consistiria na reedição (in)consciente do mito. Mas o que tal filtragem nos revelaria ao final das contas?

Meu argumento é o de que, ao se servir dos discursos literário, filosófico e científico, mas sem se confundir com esses, o pensamento de Freud tornou explícito (ou "manifesto") a contradição essencial que marca a racionalidade moderna, e que foi magistralmente exposta por Horkheimer e Adorno na Dialética do Esclarecimento. Sua obra - a psicanálise -, portanto, pode ser percebida como o esclarecimento retraduzido, (re)fletido, em sua versão "autoconsciente", ainda que isso permanecesse de certo modo alheio à consciência do próprio autor. Esse aspecto diz respeito à particular apreensão efetuada por Freud da modernidade cultural (sobretudo no que tange aos seus principais vetores, o iluminismo, o romantismo e o liberalismo), mas também toca o cerne da peculiar relação estabelecida entre o discurso psicanalítico e o mitológico.

Examinemos com cautela a peculiaridade dessa relação nos servindo do itinerário traçado por A. V. Azevedo em seus escritos sobre o tema. Conforme expôs Aristóteles em sua Poética, sublinha a autora, mýthos 
concerne tanto ao relato, ou ato de fabulação propriamente dito, quanto ao arranjo ou encadeamento desses fatos fabulosos: "por 'Mito' entendo a composição dos atos" (ARISTÓTELES, 1993, p. 39), diz-nos o filósofo. Portanto, tal composição diz respeito também à "lógica que preside à articulação significante" responsável pela produção do significado (AZEVEDO, 2004, p. 12). Nesse sentido, o significado produzido por esses "arranjos linguísticos" que ordenam os atos segundo o critério de verossimilhança tem de ser necessariamente plurívoco, de modo a ensejar inúmeras interpretações, tal como podemos auferir na esfera da produção estética ao dirigirmos nossa atenção para os diferentes períodos históricos, sobretudo no tocante às artes literárias e plásticas. Substrato discursivo de motivos, como por exemplo, a origem da vida, o sentido da morte, o enigma da diferença sexual, os mitos navegam pelas torrentes da história, inscritos na dimensão estrutural da língua (invariável), e atualizam-se nas diferentes épocas mediados pela contingência da fala, sempre pulsional e singular. Logo, "repetição" (na diferença) e "interpretação" constituem os seus principais atributos. Tais atributos certamente guardam afinidades eletivas com aquilo que também é próprio ao discurso psicanalítico.

Ao se referir à força de atração exercida pelo mito diante da psicanálise, Azevedo também asseverou que: "Tanto o mito como linguagem quanto a questão da repetição de contradições constituem pontos notáveis da atração que o discurso mítico tem exercido sobre a psicanálise. O inconsciente, a espinha dorsal dessa descoberta freudiana chamada psicanálise, também se estrutura como uma linguagem, conforme insistiu Jacques Lacan, a partir de Freud. Uma linguagem que, sobretudo, se funda no paradoxo, na coabitação de opostos e na repetição, na tendência a retornar sempre ao mesmo ponto; em geral, ao ponto de encontro com uma satisfação originária e absoluta e, portanto, mortífera" (AZEVEDO, 2004, p. 15).

Ao atentarem para o desenvolvimento da linguagem nos primórdios da humanidade, Horkheimer e Adorno (1994) de outro ângulo também chamaram atenção para o fato de que o mito representou a superação dialética da tautologia. Isto na medida em que uma árvore, em termos míticos, poderá significar para além dela mesma, outra coisa como, por exemplo, a "morada de um deus". Ou ainda, um fenômeno natural como uma tempestade poderá ser visto como sinal da ira divina em menção a um determinado episódio ocorrido no terreno dos mortais. Então, será por intermédio do mito que o pensamento tomará a forma de uma narrativa estruturada, responsável por desdobrar a linguagem em direção a uma peculiar atribuição de sentido; isso em relação tanto aos feitos humanos 
quanto aos fenômenos desencadeados em nível da natureza. Razão (in) formada pela poíeses particular aos séculos antecessores ao surgimento da pólis grega, os relatos míticos constituir-se-ão em nódulos densos de significação, sempre abertos à capacidade humana produtora de sentido.

Pois bem, visto que características fundamentais como as de repetição e de interpretação são comuns tanto aos relatos míticos como à psicanálise, avancemos mais um passo na direção dessa confluência. $\mathrm{O}$ estabelecimento de práticas culturais para relembrar o que não pode ser esquecido e que, no entanto, não pode ser também jamais totalmente decifrado, encerra outro motivo comum tanto aos rituais míticos quanto à psicanálise. Nos termos dessa última poderíamos dizer que, em ambos os casos, o que está em questão é a lembrança daquilo que constitui a dimensão da "verdade do sujeito" - alétheia (literalmente, "não esquecimento": a-léthé) ${ }^{9}$-, e que se inscreve na própria linguagem. Verdade essa que, embora parcial, opõe resistência ao puro esquecimento. No entanto, é preciso frisar que para o pensamento mítico, esquecimento e lembrança não eram tidos ainda como um fato psicológico, e sim como o produto de uma força numinosa de ocultação que se impunha aos mortais. Será por meio dos cultos ritualísticos praticados na Hélade arcaica, então, que às Musas - essas filhas de Zeus ("esplendor luminoso") com Mnemosyne ("memória") - caberá a função de trazer à lembrança aquele algo fundamental relativo à experiência humana com a verdade.

Como que antecipando o que viria a ser o moderno ritual clínico psicanalítico, lá encontraremos nas melopéias "o poder de restaurar a saúde dos enfermos, na medida em que os punha em contato com as forças primeiras e pulsantes da vida que estariam adormecidas ou esquecidas, arrancando-os da obscuridade mortífera do silêncio para inseri-los em linhagens, nos campos semânticos do que não pode ser esquecido, censurado sob pena de engendrar - como fez Discórdia, mãe de Esquecimento - dores, sofrimento, doença, lágrimas" (AZEVEDO, 2004, p. 23). Quando constatamos esse poder balsâmico emanado da palavra cantada naqueles rituais e, de outra parte, nos atemos aos principais motivos que ensejam os mitos ao longo da história, convém salientarmos, como o fez Azevedo, que o verbo grego klino, donde provém "clínica", significa "deitar, reclinar - posição privilegiada para o nascimento, a doença, o sexo, a morte, o sonho e o devaneio, experiências

9. Sobre a questão da verdade enquanto "não esquecimento" remeto o leitor para o capítulo que trata do "Simbólico" no livro de E. Porge, Jacques Lacan, Um Psicanalista (2006). 
que encontram no divã psicanalítico seu signo emblemático" (AZEVEDO, 2004, p. 16).

Para os nossos propósitos convém salientarmos ainda esse caráter apenas e sempre parcial da verdade do sujeito. Aliás, a verdade parcial é a única dita possível tanto pela psicanálise quanto pelo mito. Pois, conforme demonstrou Lacan ao interpretar o legado de Freud, na palavra que porta o desejo sempre subsistirá um resto de gozo impossível de ser expresso pela linguagem. E "isso" é o que, para ele, constituirá justamente a dimensão do "inconsciente". Já nos termos da mitologia grega as coisas se passavam evidentemente de outro modo. A parcialidade da verdade era expressa pela concepção segundo a qual aos ouvidos humanos não é dada a possibilidade de ouvir a sabedoria dos deuses, que, por já serem perfeitos, detêm a posse da verdade última sobre todas as coisas. Por esse motivo Hermes, nome que enseja a atividade hermenêutica como "arte da interpretação", será tido como o deus olímpico mensageiro e comerciante de palavras, tradutor/intérprete por excelência, a um só tempo.

Antecipamos que nos rituais mitopoéticos às Musas cabia a função de trazer à lembrança aquele algo fundamental relativo à experiência humana com a verdade. Pois bem. Uma vez evocadas pelos aedos elas representavam as verdadeiras "tecelãs" dos mitos enquanto as "gestoras da palavra" na poesia cantada. Assim concebidas, elas eram tidas como entidades capazes de "produzir palavras que, enganosamente, se assemelham aos fatos e que estão em conformidade (homoîa) com eles, como também os conformam. [...], é justamente nessa 'mentira', que busca se assemelhar aos fatos - e assim assimilá-los -, onde reside o fulcro da ficção, do encanto poético" (AZEVEDO, 2004, p. 22). E, lembremos também aqui, ainda que apenas de passagem, de outra observação feita por Lacan (1994) a propósito do caráter da verdade aos olhos da psicanálise: a verdade porta "uma estrutura de ficção". Observação essa que vem reforçar ainda mais a proximidade entre as descobertas psicanalíticas e a razão mitológica.

Além do trabalho de rememoração ensejado pelo canto mitopoético, sob o encanto das Musas também se engendrava uma imbricação temporal entre o presente, o passado e o futuro. Nesse aspecto, Azevedo nos faz notar que, tal como na poesia, também a fantasia comandada pelo desejo é regida pela imbricação dos três tempos. Ambas (poesia e fantasia, incluindo-se as fabulações oníricas) são produções criativas alimentadas por experiências pregressas. E é isso que, de certo modo, encerrará todo ato criativo numa re-criação. Traço fundamental que o poeta arcaico (aedo) vem compartilhar com o analisante moderno: "ambos seguidores 
e praticantes dos ritos de memória como encarnação figurada do que se inscreveu, sem escrita. O discurso mito-poético e a fala, mitos, do analisante são criações em que se recriam as relações fundamentais, e por isso indeléveis, do humano; em suma são criações que buscam religar o homem às forças originais, vitais, a Eros" (AZEVEDO, 2004, pp. 26-27).

Mas se podemos aceitar a evidência de que a psicanálise compartilha com o mito o sentido da "cura pela palavra", sobretudo a partir daquelas experiências que resistem ao esquecimento, e que, portanto, clamam por rememoração a fim de poderem ser ressignificadas, por outro lado, os construtos psicanalíticos também acrescentam novas camadas interpretativas aos mitos antigos. Como bem notou L. Strauss, argumento retomado por Lacan, não seria exagero algum incluir Freud após Sófocles entre as fontes apropriadas para recuperação do mito de Édipo (LACAN, 1987 , p. 28). Contudo se os construtos psicanalíticos acrescem algo às interpretações anteriores do mito de Édipo, não se pode esquecer que é do lugar da ciência que a versão freudiana do "complexo" foi elaborada. Nesse ponto, as confluências entre os discursos psicanalítico e literário cessam. Por mais que o mito contivesse uma dimensão terapêutica nos períodos de convalescença, ou mesmo um potencial de cura em determinadas culturas que deles se serviram, ou que deles ainda se servem para esse fim, a poesia enquanto gênero literário distinto da prosa não se confunde com os intentos da medicina. E foi dessa última que a psicanálise herdou a noção sanitária de "sintoma". Mas que especificidade porta esse termo para a psicanálise?

Conforme a etimologia grega da palavra, sintoma indica "o que caminha junto". Numa carta a Jung datada de 15 de Julho de 1911, Freud afirma que: "Os sintomas não resultam diretamente das recordações, mas de fantasias que são construídas sobre elas" (MIJOLLA, 2005, p. 1.745). Isto significa que a noção psicanalítica de sintoma aponta para uma semiologia composta pelos sentidos médico e linguístico. Os sintomas, esses índices perturbadores da nossa existência, essas manifestações problemáticas aparentemente sem razão, "caminham junto" ao sujeito como resultantes de determinadas formações psíquicas. Eis aí o ponto em que a ciência enredada pelo seu método de construção do saber estancava aos olhos de Freud. Motivo que o levou à construção de toda sua metapsicologia a partir da noção hipotética de "inconsciente".

Retornemos à XXXII conferência em que Freud se referiu à sua teoria das pulsões como sendo a "nossa mitologia". Aí, como vimos, ele assume o caráter ficcional de seus constructos de tal modo que o emprego do termo "fantasia exata", tal como utilizado por Adorno emprestando-o de Goethe, poderia muito bem nos servir para expressar essa zona de 
intersecção positiva entre o mito e o esclarecimento, a propósito da relação entre a psicanálise e a teoria crítica. Pois, se a pulsão encerra um "conceito limite entre o psíquico e o somático", como a definiu Freud, esse "entre", a rigor, quer dizer que a pulsão encontra no corpo a sua fonte e no psíquico o seu registro. Isto é, não se trata de um conceito redutível nem ao psíquico nem ao biológico. Trata-se antes de uma "ficção teórica", ou de uma produção conceitual própria ao arcabouço da psicanálise.

Se esse conceito fictício tão caro à psicanálise chamou a atenção de Adorno, e também de Horkheimer, e lhes pareceu tão apropriado para esclarecer a psicologia do indivíduo massificado sob a batuta da indústria cultural como versão do anti-semita perante o Führer, dentre tantos outros fenômenos, talvez seja pertinente visualizarmos nessa zona de intersecção positiva partilhada entre o mito e o esclarecimento, ou melhor, entre o mito e o ímpeto esclarecedor próprio à psicanálise algo de essencial que essa última pôde oferecer à teoria crítica. Algo que, tal como uma mônada cerrada em si, porta uma opacidade específica que nos obriga à referência apenas por metáforas aproximativas. Um conceito que "[a]ssim como aponta para a teoria, [...] aponta também para algo que se furta ao olhar conceitual", observou certa vez G. Rosa (ROSA, 1999, p. 14). E, do nosso ponto de vista, tão ao sabor da Dialética Negativa de Adorno.

\section{REFERÊNCIAS BIBLIOGRÁFICAS}

ADORNO, Theodor W. Dialética negativa. Tradução: Marco Antonio Casanova. Rio de Janeiro: Zahar, 2009.

ARISTÓTELES. Poética. Tradução: Eudoro de Souza. Segunda Edição. São Paulo: Ars Poética, 1993.

AZEVEDO, Ana V. de. Mito e psicanálise. Rio de Janeiro: Jorge Zahar Editor, 2004.

BUCK-MORSS, Susan. Origen de la dialéctica negativa: Theodor W. Adorno, Walter Benjamin y El Instituto de Frankfurt. México: Siglo XXI, 1981.

FREUD, Sigmund. Ensaios de metapsicologia. In: Obras completas, v. 12. Tradução: Paulo Cesar de Souza. São Paulo: Companhia das Letras, 2010. . Lecciones introductorias al psicoanálisis. In: Obras Completas. Tomo II. Tradução: Luiz Lopez-Ballesteros y de Torres. Quarta Edição. Madrid: Biblioteca Nueva, 1981. . Tres ensayos para una teoría sexual. In: Obras Completas. Tomo II. Tradução: Luiz Lopez-Ballesteros y de Torres. Quarta Edição. Madrid: Biblioteca Nueva, 1981. . Autobiografía. In: Obras Completas. Tomo III. Tradução: Luiz Lopez-Ballesteros y de Torres. Quarta Edição. Madrid: Biblioteca Nueva, 1981. 


$$
160 \text { - Remate de Males } 30.1
$$

GAGNEBIN, Jeanne M. Lembrar, escrever, esquecer. São Paulo: Editora 34, 2006.

HESÍODO. Teogonia. Tradução: Jaa Torrano. São Paulo: Iluminuras, 2006.

HORKHEIMER, Max; ADORNO, Theodor W. Dialética do esclarecimento. Tradução: Guido A. de Almeida. Rio de Janeiro: Jorge Zahar Editor, 1985.

KNOLBLOCH, Felícia (org.). O inconsciente: várias leituras. São Paulo: Escuta, 1991.

LACAN, Jacques. Seminario XVIII. De un discurso que no fuera del semblante. Tradução: Nora A. González. Barcelona: Paidós, 2009. . Escritos. Tradução: Vera Ribeiro. Rio de Janeiro: Jorge Zahar Editor, 1998. . O mito individual do neurótico. Tradução: Brigite C. e Cunha, Fernanda Bernardo, Margarida Medeiros, Tito C. e Cunha. Rio de Janeiro: Jorge Zahar Editor, 1987.

LONITZ, H. Theodor W. Adorno and Walter Benjamin: the complete correspondence 1928 - 1940. Tradução: Nicholas Walker. Cambridge, Massachusetts: Harvard University Press, 1999.

MIJOLLA, Alain de. Dicionário Internacional da Psicanálise. Trad. Álvaro Cabral. Rio de Janeiro: Imago, 2005 .

NOVAES, Adauto (org.). Mutações. São Paulo: Edições SESC-SP, 2007.

PORGE, Erik. Lacan, um psicanalista: percurso de um ensino.Tradução: Cláudia T.G. de Lemos, Nina V. de A. Leite, Viviane Veras. Brasília: Ed. UnB, 2006.

ROSA, Luiz A. G. Acaso e repetição em psicanálise: uma introdução à teoria das pulsões. Rio de Janeiro: Jorge Zahar, 1999.

WIGGERHAUS, Rolf. A Escola de Frankfurt. Tradução: Lilyane Deroche-Gurcel. Rio de Janeiro: Ed. Bertrand Brasil Ltda., 2002. 